\title{
Kinetics and Mechanism of the Decomposition of Chlorous Acid
}

\author{
Attila K. Horváth,$^{\dagger}$ István Nagypál, ${ }^{*, \dagger}$ Gábor Peintler,$^{\dagger}$ Irving R. Epstein, ${ }^{*, ‡}$ and \\ Kenneth Kustin
}

University of Szeged, Department of Physical Chemistry, Szeged P.O. Box 105, H-6701, Hungary, and Brandeis University, MS 015, Department of Chemistry, Waltham, Massachusetts 02454-9110

Received: November 7, 2002; In Final Form: June 27, 2003

\begin{abstract}
The kinetics of decomposition of aqueous chlorous acid has been reinvestigated at $\mathrm{pH} 0.7-1.9$, ionic strength $1.0 \mathrm{M}\left(\mathrm{HSO}_{4}{ }^{-} / \mathrm{SO}_{4}{ }^{2-}\right)$, and temperature $25.0 \pm 0.1{ }^{\circ} \mathrm{C}$. Optical absorbances were collected in the $240-450$ $\mathrm{nm}$ wavelength range for up to $\sim 90 \%$ decomposition for time series lasting as long as 2 days. The number of absorbing species was investigated by matrix rank analysis; no absorbing intermediate was formed in significant concentration during the decomposition. Of the many mechanistic models tested, the one that fit best included the following reactive intermediates: $\mathrm{HOCl}, \mathrm{Cl}_{2} \mathrm{O}_{2}, \mathrm{Cl}_{2} \mathrm{O}_{3},{ }^{\circ} \mathrm{ClO},{ }^{\circ} \mathrm{OH}$. The stoichiometric ratio of $\mathrm{ClO}_{2}$ produced to $\mathrm{Cl}(\mathrm{III})$ consumed varies with $\mathrm{pH}$ and $\left[\mathrm{Cl}^{-}\right]$. Reaction of $\mathrm{Cl}_{2} \mathrm{O}_{3}$ with $\mathrm{Cl}$ (III) yields chlorate exclusively. Reaction of $\mathrm{Cl}_{2} \mathrm{O}_{3}$ with $\mathrm{Cl}^{-}$favors $\mathrm{ClO}_{2}$ over chlorate, but does not entirely exclude chlorate, because it is produced by hydrolysis of $\mathrm{Cl}_{2} \mathrm{O}_{2}$. Invoking $\mathrm{Cl}_{2} \mathrm{O}_{3}$ explains the variation in stoichiometric ratio as well as the maximum observed in the initial rate of $\mathrm{ClO}_{2}$ formation as a function of $\mathrm{pH}$. The kinetics of chlorous acid decomposition cannot be quantitatively fit through the last stages of the reaction without postulating a first-order decomposition. Scission of chlorous acid to give short-lived hydroxyl and chlorine(II) monoxide is a plausible route for this process. A set of best-fit and literature-derived parameters is presented for the complete mechanism.
\end{abstract}

\section{Introduction}

Chlorine(III)-driven oscillators comprise the largest family of chemical oscillators, ${ }^{1}$ and the mechanisms developed to explain their dynamical behavior are in fairly good agreement with the data. ${ }^{2-4}$ For such oscillators at $\mathrm{pH} 4$ or below, the amount of chlorine(III) present in solution in the form of chlorous acid $\left(\mathrm{HClO}_{2}\right)$ is significant, and its rate of decomposition must be known to a relatively high degree of accuracy to improve the quality of data-fitting. However, despite many excellent kinetics studies, ${ }^{5-7}$ a full picture of the kinetics of $\mathrm{HClO}_{2}$ decomposition over a wide range of conditions and reaction lifetimes has not been ${ }^{8}$ and is not yet available.

Crucial to framing an adequate model of chlorine(III) reactions is knowledge of relevant short- and long-lived intermediates. In revealing the existence of one such short-lived species, unsymmetrical $\mathrm{Cl}_{2} \mathrm{O}_{2}$, Taube and Dodgen provided experimental evidence for a versatile intermediate, ${ }^{9}$ the reactions of which lead to diverse products. For example, reduction of unsymmetrical $\mathrm{Cl}_{2} \mathrm{O}_{2}$ by $\mathrm{I}_{2}$ produces $\mathrm{HOCl} .{ }^{4}$ Oxidation of unsymmetrical $\mathrm{Cl}_{2} \mathrm{O}_{2}$ by chlorine(III), for example, produces chlorine dioxide. ${ }^{9}$ Hydrolysis of unsymmetrical $\mathrm{Cl}_{2} \mathrm{O}_{2}$ leads to formation of chlorate and chloride ions. ${ }^{9}$ A potential intermediate of equal versatility, but one which has been relegated to insignificance, ${ }^{8}$ is longer-lived $\mathrm{Cl}_{2} \mathrm{O}_{3}$, which is indefinitely stable at $-78{ }^{\circ} \mathrm{C} .{ }^{10} \mathrm{~A}$ reinvestigation of the kinetics of $\mathrm{HClO}_{2}$ decomposition using improved experimental and computational techniques offers us the opportunity to improve the quality of data-fitting and to reevaluate the relative importance of these two intermediates in the mechanism of this reaction.

\footnotetext{
* Authors to whom correspondence should be addressed. E-mail: nagypal@chem.u-szeged.hu; epstein@brandeis.edu.

University of Szeged.

Brandeis University.
}

\section{Experimental Section}

Materials and Buffers. Commercially available Aldrich $\mathrm{NaClO}_{2}$ was purified as described previously. ${ }^{11}$ The purity of $\mathrm{NaClO}_{2}$ was checked by standard iodometric titration and found to be better than $99.9 \%$. No chloride impurities could be detected in the purified $\mathrm{NaClO}_{2}$. All other chemicals $\left(\mathrm{H}_{2} \mathrm{SO}_{4}, \mathrm{Na}_{2} \mathrm{SO}_{4}\right.$, $\mathrm{NaCl}$ ) were of the highest purity available (Aldrich) and were used without further purification.

Earlier studies of the oscillatory behavior of chlorite-driven systems were conducted at about $\mathrm{pH} 2$, adjusted with sulfuric acid. Therefore, $\mathrm{HSO}_{4}{ }^{-} / \mathrm{SO}_{4}{ }^{2-}$ buffer was used to maintain the $\mathrm{pH}$ between 0.7 and 1.9 at $1.0 \mathrm{M}$ ionic strength taking the $\mathrm{p} K_{\mathrm{a}}$ of $\mathrm{HSO}_{4}{ }^{-}$as $1.24 .^{12}$ Table 1 shows the initial composition of the solutions studied, including concentrations of buffer components.

Methods and Instrumentation. Solutions for kinetics runs $\left(25.0 \pm 0.1{ }^{\circ} \mathrm{C}\right)$ were prepared in a $10-\mathrm{mm}$ quartz cuvette equipped with a Teflon screw cap and a magnetic stirrer. The screw cap of the cuvette was carefully sealed with Parafilm to minimize the loss of chlorine dioxide during the 2-day runs. Between data acquisition intervals, the thermostated cuvette was stored in complete darkness to avoid any photochemical decomposition of chlorine dioxide. ${ }^{13}$ A Hewlett-Packard (HP) 8452 A diode array spectrophotometer was used to record 3035 spectra for up to 2 days. The first spectrum was always recorded within $15 \mathrm{~s}$ of the start of each experimental run. The initial concentrations of chlorite/chlorous acid and chloride are collected in Table 1. The molar absorbance of ${ }^{\bullet} \mathrm{ClO}_{2}$ at $2 \mathrm{~mm}$ intervals in the wavelength range $248-450 \mathrm{~nm}$ was calculated from absorbance data measured in 13 different solutions in the concentration range $0.00015-0.02 \mathrm{M}$. In this way, the molar absorbance calculated at every wavelength is the average of $3-8$ experimental data points. No concentration dependence of the 
TABLE 1: Initial Composition (M) of Solutions Used in Kinetics Experiments

\begin{tabular}{lccll}
\hline no. & {$\left[\mathrm{Na}_{2} \mathrm{SO}_{4}\right]_{0}$} & {$\left[\mathrm{H}_{2} \mathrm{SO}_{4}\right]_{0}$} & \multicolumn{1}{c}{$\left[\mathrm{NaClO}_{2}\right]_{0}$} & \multicolumn{1}{c}{$[\mathrm{NaCl}]_{0}$} \\
\hline $1-4$ & 0.3229 & 0.3678 & $0.001,0.002,0.004,0.008$ & 0 \\
$5-6$ & 0.3229 & 0.3678 & 0.004 & $0.001,0.003$ \\
$7-10$ & 0.3407 & 0.2738 & $0.001,0.002,0.004,0.008$ & $0.001,0.003$ \\
$11-12$ & 0.3407 & 0.2738 & 0.004 & $0,0.001,0.003,0.01$ \\
$13-28$ & 0.3461 & 0.1973 & $0.001,0.002,0.004,0.008$ & $0.001,0.003,0.01$ \\
$29-32$ & 0.3458 & 0.1376 & $0.001,0.002,0.004,0.008$ & 0 \\
$33-35$ & 0.3458 & 0.1376 & 0.004 & $0.001,0.003,0.01$ \\
$36-39$ & 0.3433 & 0.0932 & $0.001,0.002,0.004,0.008$ & 0.004 \\
$40-42$ & 0.3433 & 0.0932 & $0.001,0.002,0.004,0.008$ & $0.001,0.003,0.01$ \\
$43-46$ & 0.3406 & 0.0618 & 0.004 & 0 \\
$47-49$ & 0.3406 & 0.0618 & $0.001,0.002,0.004,0.008$ & $0.001,0.003,0.01$ \\
$50-53$ & 0.3384 & 0.0403 & 0.004 &
\end{tabular}

molar absorptivity coefficients was found. The molar absorbance of chlorite ion was determined in a similar way between 240 and $360 \mathrm{~nm}$ from the spectra of $14 \mathrm{NaClO}_{2}$ solutions in the $0.001-0.01 \mathrm{M}$ concentration range at $\mathrm{pH} 6$ in acetate buffer.

\section{Data Treatment}

For the HP 8452A spectrophotometer, the constant uncertainty in absorbance is \pm 0.004 absorbance units. As the absorbance increases beyond unity, the transmitted light intensity decreases and circuit noise begins to limit the precision with which the absorbance can be measured. For this reason we set an upper limit of 1.3 absorbance units, beyond which no kinetics data was collected. The first procedure in the treatment of collected data was to extrapolate the first five experimental points to time $t=0$ to determine the initial absorbance. These initial $(t=0)$ data were then used with the program PSEQUAD ${ }^{14}$ for the simultaneous calculation of the $\mathrm{p} K_{\mathrm{a}}$ of chlorous acid and its molar absorbance between 240 and $420 \mathrm{~nm}$.

The next procedure of the data treatment was to apply matrix rank analysis to the absorbance-time data series to determine the number of absorbing species. ${ }^{15}$ When the measurements were evaluated at only a single $\mathrm{pH}$, the rank was found to be 2 . The $\left[\mathrm{ClO}_{2}{ }^{-}\right] /\left[\mathrm{HClO}_{2}\right]$ ratio is constant in this case, making it impossible to distinguish between chlorite ion and chlorous acid by a linear algebraic method. When the experimental data collected at all $\mathrm{pH}$ values were evaluated simultaneously, the rank was found to be 3 . These results unambiguously demonstrate that no absorbing intermediate is formed in significant concentration during the decomposition, since the third species must be chlorine dioxide, because it alone absorbs strongly between 240 and $450 \mathrm{~nm}$.

Data were collected at $248 \mathrm{~nm}$ (the closest wavelength to the isosbestic point of the chlorite/chlorous acid system) and at $420 \mathrm{~nm}$ (where only chlorine dioxide has significant light absorption). The two selected wavelengths carry all the important kinetics information on the absorbing species that can be gained from the whole $240-450 \mathrm{~nm}$ range. These data were then used to carry out the fitting procedure by $\mathrm{ZiTa},{ }^{16}$ a program developed for fitting kinetics curves. Altogether, 3130 experimental data points were collected in 112 such absorbance-time series.

The data-fitting procedure was as follows. A sequence of rate functions, corresponding to the steps in a particular mechanism, and including as small a number of parameters to be fitted as possible, was numerically integrated yielding a concentrationtime series. These calculated concentrations and relevant measured molar absorbances were used to construct an absorbance-time series. The parameters to be fitted were then adjusted so as to minimize the sum of the squares of differences between measured and calculated absorbances (average deviation). The criterion for the goodness of fit was to reach the

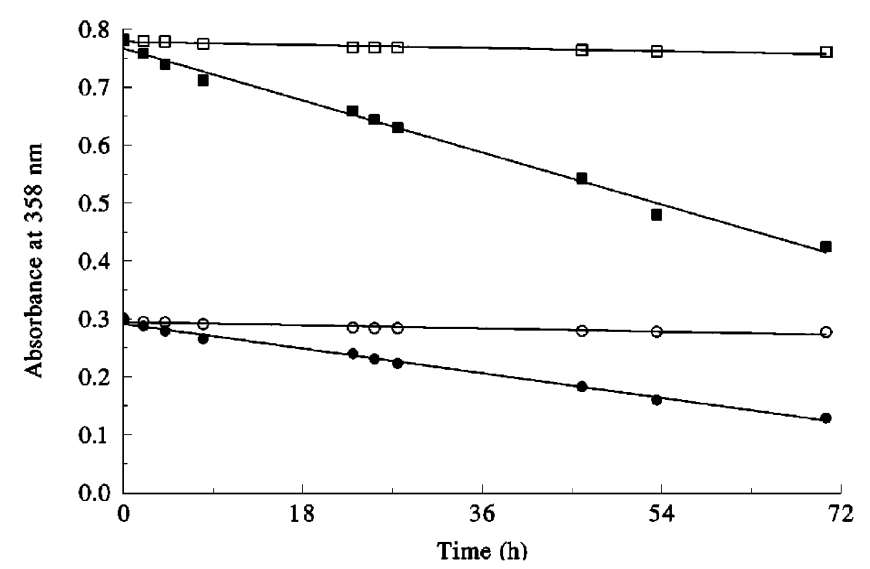

Figure 1. Loss of chlorine dioxide from the cuvette in the absence $(\mathrm{O}),(\square)$ and presence $(\bullet),(\boldsymbol{\square})$ of room light. $\left[{ }^{\circ} \mathrm{ClO}_{2}\right]_{0}=0.00024 \mathrm{M}$ $(\mathrm{O}),(\bullet) ; 0.000625 \mathrm{M}(\square),(\mathbf{\square})$.

uncertainty $( \pm 0.004)$ of the spectrophotometer with average deviation as close as it could be. In addition to providing a good fit of the data, a mechanism was required to model trends in the data, such as dependences on $\mathrm{pH}$ and initial concentrations.

\section{Results}

Loss of Chlorine Dioxide. Solutions of chlorine dioxide are well-known to be photochemically degraded. ${ }^{17}$ Transmission of spectrophotometric light through the filled cuvette can drive photochemical decomposition. Therefore it was necessary to determine the unavoidable loss of chlorine dioxide during the 2-day runs. The absorbance of chlorine dioxide solutions - in a tightly closed and carefully cleaned quartz cuvette-was followed when the solution was kept (a) in total darkness and (b) in ordinary room light for 3 days (Figure 1). In room light, the rate of loss of ${ }^{\circ} \mathrm{ClO}_{2}$ was more than an order of magnitude greater than when the solutions were stored in the dark. When light was almost totally excluded (it is impossible to exclude light during data acquisition), the small loss of ${ }^{\bullet} \mathrm{ClO}_{2}$ obeys zeroorder kinetics with a rate constant of $6.8 \times 10^{-11} \mathrm{Ms}^{-1}$. This result is in excellent agreement with Stanbury and Figlar's work, ${ }^{13}$ and also supports our constructing the experimental setup to avoid as much light as possible. Moreover, it implies that the decrease in absorbance due to loss of ${ }^{\circ} \mathrm{ClO}_{2}$ at 248 and $420 \mathrm{~nm}$ is less than 0.003 absorbance unit over a 2-day run, which is close to the intrinsic uncertainty of an absorbance measurement. Consequently, no correction for loss of ${ }^{\bullet} \mathrm{ClO}_{2}$ was made in the data evaluation.

$\mathrm{p} K_{\mathrm{a}}$ Calculation and Spectra. The result of one $\mathrm{p} K_{\mathrm{a}}$ calculation is shown in Figure 2. The negative logarithm of the calculated acidic dissociation constant of chlorous acid in our medium is $1.86 \pm 0.01$. The molar absorbances obtained for ${ }^{\circ} \mathrm{ClO}_{2}, \mathrm{ClO}_{2}{ }^{-}$, and $\mathrm{HClO}_{2}$ are shown in Figure 3. 


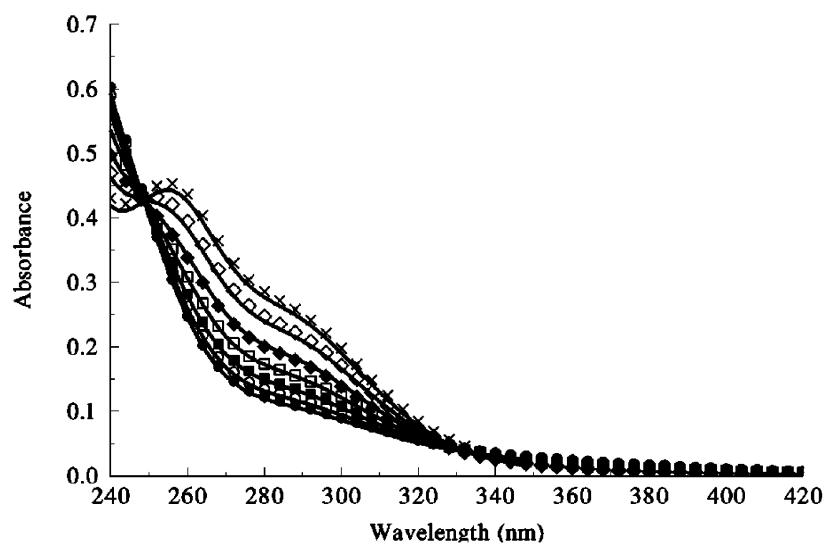

Figure 2. Experimentally measured (symbols) and calculated (lines) spectra of $0.004 \mathrm{M} \mathrm{NaClO}_{2}$ at different $\mathrm{pH}$ values: $\mathrm{pH}=0.7(\bullet), 0.9$ (○), $1.1(\square), 1.3(\square), 1.5(\diamond), 1.7(\diamond), 1.9(\times)$.

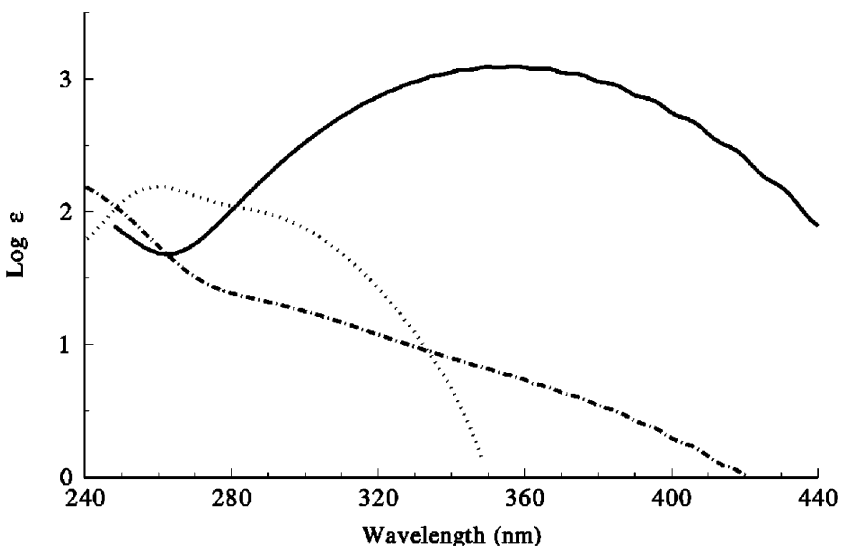

Figure 3. Calculated molar absorbances of chlorite (dotted line), chlorous acid (dot-dashed line), and chlorine dioxide (solid line).

Stoichiometry. Several groups of investigators ${ }^{5-7}$ have found that in the absence of chloride ion the stoichiometry of the decomposition of chlorous acid is given by reaction $\mathrm{A}$ :

$$
4 \mathrm{HClO}_{2} \rightarrow 2^{\bullet} \mathrm{ClO}_{2}+\mathrm{ClO}_{3}^{-}+\mathrm{Cl}^{-}+2 \mathrm{H}^{+}+\mathrm{H}_{2} \mathrm{O}
$$

The stoichiometry of the decomposition of chlorous acid in the presence of chloride ion is given by reaction $\mathrm{B}$ :

$$
5 \mathrm{HClO}_{2} \rightarrow 4^{\bullet} \mathrm{ClO}_{2}+\mathrm{Cl}^{-}+\mathrm{H}^{+}+2 \mathrm{H}_{2} \mathrm{O}
$$

An appropriate linear combination of these reactions should describe the stoichiometry. If this set of reactions is complete, then the stoichiometric ratio (SR) must always lie between 0.5 and 0.8 , where $\mathrm{SR}=$ ratio of quantity of ${ }^{\circ} \mathrm{ClO}_{2}$ formed to quantity of chlorine(III) consumed. Earlier studies, ${ }^{9,18}$ in agreement with our present results, have also found the formation of more chlorate than predicted from reaction $\mathrm{A}$. Reaction $\mathrm{C}$

$$
3 \mathrm{HClO}_{2} \rightarrow 2 \mathrm{ClO}_{3}^{-}+\mathrm{Cl}^{-}+3 \mathrm{H}^{+}
$$

also plays a role in determining the stoichiometry at higher $\mathrm{HClO}_{2}$ concentrations.

Kinetics Curves and Stoichiometric Ratios. Absorbances measured at 248 and $358 \mathrm{~nm}$ (and shown in the figures) were transformed into actual concentrations for analysis of the initial rates of $\mathrm{Cl}(\mathrm{III})$ consumption and ${ }^{\bullet} \mathrm{ClO}_{2}$ formation.

The rate of consumption of chlorine(III), i.e., $\left[\mathrm{HClO}_{2}\right]+$ $\left[\mathrm{ClO}_{2}^{-}\right]$, steadily increases with decreasing $\mathrm{pH}$ (Figure 4). However, several authors ${ }^{5,18,19}$ have noted previously that in the absence of chloride ion the initial rate of chlorine dioxide

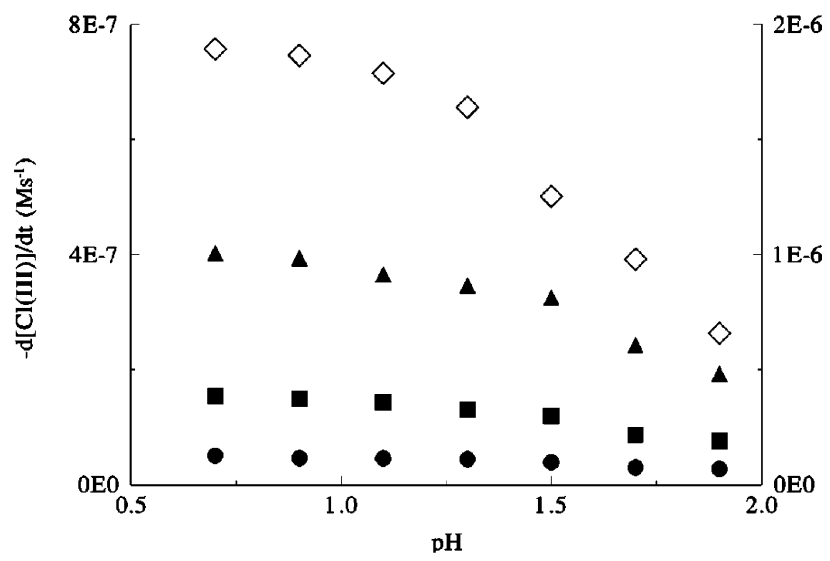

Figure 4. Initial rates of $\mathrm{Cl}(\mathrm{III})$ consumption in the absence of chloride ion: $\left[\mathrm{HClO}_{2}\right]_{0}+\left[\mathrm{ClO}_{2}^{-}\right]_{0}(\mathrm{M})=0.001(\bullet), 0.002(\boldsymbol{\square}), 0.004(\mathbf{\Delta})$, $0.008(\diamond)$. Left vertical axis refers to filled symbols; right vertical axis refers to unfilled symbols.

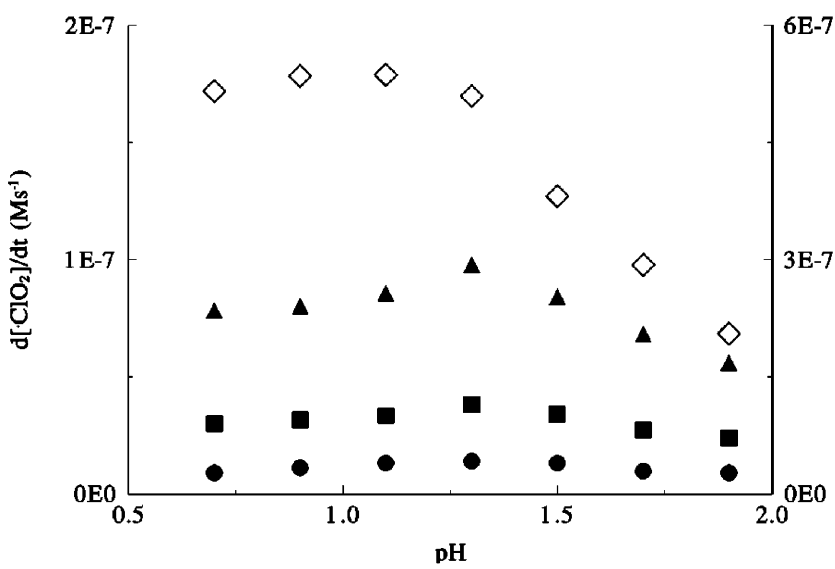

Figure 5. Initial rates of chlorine dioxide formation in the absence of chloride ion. $\left[\mathrm{HClO}_{2}\right]_{0}+\left[\mathrm{ClO}_{2}^{-}\right]_{0}=0.001(\bullet), 0.002(\boldsymbol{\square}), 0.004(\mathbf{\Delta})$, $0.008(\diamond)(\mathrm{M})$. Left vertical axis refers to filled symbols; right vertical axis refers to unfilled symbols.

formation goes through a maximum as a function of $\mathrm{pH}$ (Figure 5). In the entire $\mathrm{pH}$ range, the presence of chloride ion in the initial solution decreases the initial rate, but increases significantly the conversion of $\mathrm{Cl}(\mathrm{III})$ to chlorine dioxide. Thus $\mathrm{Cl}^{-}$ has a simultaneous inhibitory and catalytic effect on the decomposition of chlorous acid, in agreement with earlier studies. $^{5,6}$ Moreover, the initial rate of decomposition goes through a minimum as a function of initial chloride concentration (Figure 6) as was noted by Hong and Rapson. ${ }^{6}$

Additional stoichiometric observations can be summed up by the following trends in the stoichiometric ratio, SR. (1) SR always decreases during the course of the reaction and, as expected, the first measured value (at $t=15 \mathrm{~s}$ ) decreases with decreasing [Cl(III)] (Figure 7a). (2) SR increases with increasing $\mathrm{pH}$ (Figure 7b). (3) SR is considerably higher if chloride ion is present initially and increases with increasing $\left[\mathrm{Cl}^{-}\right]$(Figure $7 \mathrm{c}$ ).

\section{Mechanism}

Previous Mechanisms. The two most comprehensive efforts $^{5,6}$ to unravel the mechanism of the noncatalytic decomposition of chlorous acid are based on initial rate studies, not on the complete concentration-time series. More recently, the decomposition of chlorous acid has been studied at high acidity ${ }^{20}$ (4.5 M sulfuric acid solution), and the effect of chloride ion on chlorine dioxide formation has been discussed. ${ }^{20,21}$ Except in the studies of Kieffer and Gordon, ${ }^{5}$ only the concentration of chlorine dioxide was followed. 

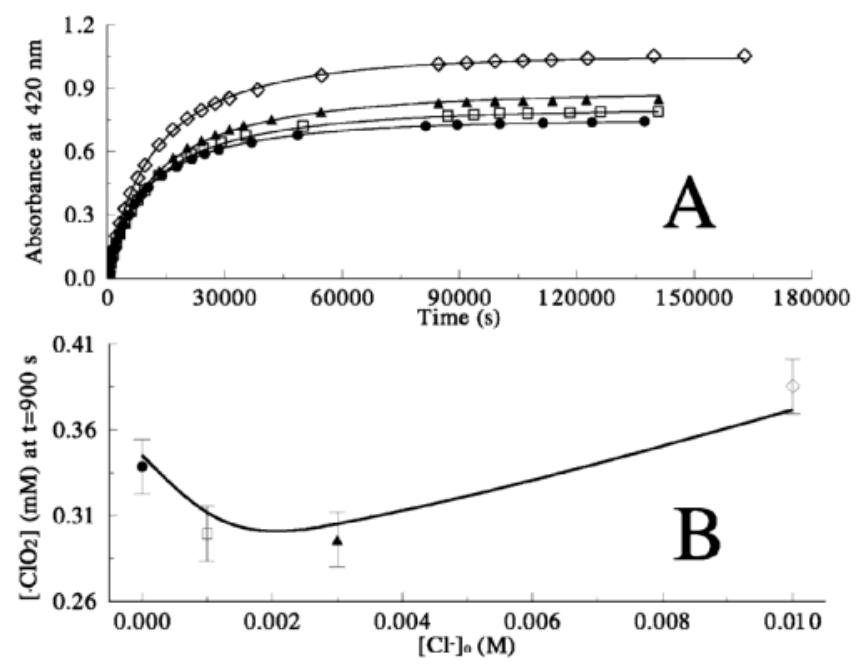

Figure 6. (A) Experimentally measured (symbols) and calculated (solid lines) absorbances at $\left[\mathrm{HClO}_{2}\right]_{0}+\left[\mathrm{ClO}_{2}^{-}\right]_{0}=0.008 \mathrm{M}$ and $\mathrm{pH}=1.1$ with different initial chloride concentrations: $\left[\mathrm{Cl}^{-}\right]_{0}=0(\bullet), 0.001$ $(\square), 0.003(\mathbf{\Delta}), 0.01(\diamond)(\mathrm{M})$. (B) Experimentally measured (pointssymbols as in (A) and calculated (solid line) $\left[{ }^{\circ} \mathrm{ClO}_{2}\right]$ at $t=900 \mathrm{~s}$ at different initial chloride concentrations at $\mathrm{pH}=1.1$ and $\left[\mathrm{HClO}_{2}\right]_{0}+$ $\left[\mathrm{ClO}_{2}^{-}\right]_{0}=0.008 \mathrm{M}$.

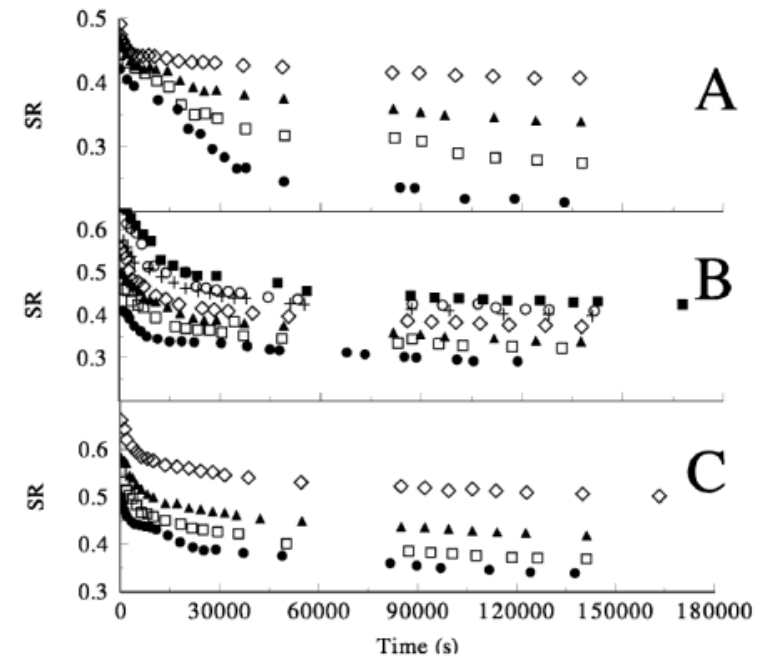

Figure 7. (A) Stoichiometric ratio (SR) in the absence of initial chloride at $\mathrm{pH}=1.1$ at several $\left[\mathrm{HClO}_{2}\right]_{0}+\left[\mathrm{ClO}_{2}{ }^{-}\right]_{0}$ values: $\left[\mathrm{HClO}_{2}\right]_{0}$ $+\left[\mathrm{ClO}_{2}^{-}\right]_{0}=0.001(\bullet), 0.002(\square), 0.004(\mathbf{\Delta}), 0.008(\diamond)(\mathrm{M}) .(\mathrm{B})$ Stoichiometric ratio (SR) at $\left[\mathrm{HClO}_{2}\right]_{0}+\left[\mathrm{ClO}_{2}{ }^{-}\right]_{0}=0.004 \mathrm{M}$ in the absence of initial chloride at different $\mathrm{pH}$ values. $\mathrm{pH}=0.7(\bullet), 0.9$ $(\square), 1.1(\mathbf{\Delta}), 1.3(\diamond), 1.5(+), 1.7(\bigcirc), 1.9(\square)$. (C) Stoichiometric ratio $(\mathrm{SR})$ at $\mathrm{pH}=1.1$ and $\left[\mathrm{HClO}_{2}\right]_{0}+\left[\mathrm{ClO}_{2}^{-}\right]_{0}=0.004 \mathrm{M}$ at different initial chloride concentrations: $\left[\mathrm{Cl}^{-}\right]_{0}=0(\bullet), 0.001(\square), 0.003(\mathbf{\Delta})$, $0.01(\diamond)(\mathrm{M})$.

Kieffer and Gordon followed the change of concentration of chlorous acid and chlorine dioxide simultaneously, but their mechanistic analysis and proposed rate equation were based on the consumption of chlorous acid only. They found a two-term rate law, eq KG1:

$$
\begin{aligned}
-\mathrm{d}\left[\mathrm{HClO}_{2}\right] / \mathrm{d} t=k\left[\mathrm{HClO}_{2}\right]^{2}+k^{\prime}\left[\mathrm{HClO}_{2}\right]\left[\mathrm{Cl}^{-}\right]^{2} / \\
\left(K_{\mathrm{a}}+\left[\mathrm{Cl}^{-}\right]\right)(\mathrm{KG} 1)
\end{aligned}
$$

Their proposed mechanism contains an initiating bimolecular $\mathrm{HClO}_{2}$ self-reaction step that generates $\mathrm{HOCl}$ to explain the first term. Following initiation, a sequence of steps was proposed that accounts for the $\left[\mathrm{H}^{+}\right]$- and $\left[\mathrm{Cl}^{-}\right]$-dependences of the second term. Over the experimental range investigated by Kieffer and Gordon, their mechanism describes the behavior of the system quite well.
Instead of following the disappearance of chlorous acid, Hong and Rapson followed the formation of chlorine dioxide only and used initial rate measurements to obtain a complicated rate equation (HR1):

$$
\begin{aligned}
\mathrm{d}\left[{ }^{\bullet} \mathrm{ClO}_{2}\right] / \mathrm{d} t=k_{\mathrm{a}}\left[\mathrm{HClO}_{2}\right]^{2}+k_{\mathrm{b}}\left[\mathrm{HClO}_{2}\right]\left[\mathrm{ClO}_{2}^{-}\right]+ \\
k_{\mathrm{c}}\left[\mathrm{H}^{+}\right]\left[\mathrm{HClO}_{2}\right]\left[\mathrm{Cl}^{-}\right]\left\{1-\left[\mathrm{Cl}^{-}\right] /\left(k_{\mathrm{d}}\left[\mathrm{HClO}_{2}\right] /\left[\mathrm{H}^{+}\right]+\right.\right. \\
\left.\left.k_{\mathrm{r}}\left[\mathrm{H}^{+}\right]\right)\right\}(\mathrm{HR} 1)
\end{aligned}
$$

for formation of chlorine dioxide. Their proposed mechanism initiates decomposition with a bimolecular $\mathrm{HClO}_{2}$ self-reaction leading to the identical products as in the Kieffer and Gordon mechanism. Both Kieffer and Gordon and Hong and Rapson invoke formation of a $\mathrm{Cl}_{2} \mathrm{O}_{2}$ intermediate, but differ in the proposed reactions of this transient species. The Hong and Rapson mechanism also describes the behavior of the system within their experimental range quite well.

Proposed Mechanism. Our first attempts to analyze our experiments were based on these two mechanisms, but neither gave acceptable results when the whole time series was used and the consumption of $\mathrm{Cl}(\mathrm{III})$ and the formation of chlorine dioxide were evaluated simultaneously.

The approach we have taken here, which resembles more some of the techniques used to construct large models in atmospheric $^{22}$ or combustion ${ }^{23}$ chemistry than the earlier mechanistic studies of chlorous acid decomposition, takes advantage of the significant advances in computing power. We began by supposing a dozen or so relevant species, and postulated roughly 70 feasible mono- and bimolecular reactions among these species. For each reaction we considered uncatalyzed, chloride- and proton-catalyzed paths, as well as combined chloride- and proton-catalysis. Altogether we evaluated approximately 300 reactions. A mechanism was developed from this set of species and reactions by assigning plausible rate constants to all reactions and then investigating the relative contribution of each reaction to the accuracy of the fit. The results of this procedure lead us to propose the following mechanism:

$$
\begin{aligned}
& \mathrm{HSO}_{4}^{-} \leftrightarrow \mathrm{H}^{+}+\mathrm{SO}_{4}^{2-} \\
& \mathrm{HClO}_{2} \leftrightarrow \mathrm{H}^{+}+\mathrm{ClO}_{2}^{-} \\
& 2 \mathrm{HClO}_{2} \leftrightarrow \mathrm{Cl}_{2} \mathrm{O}_{3}+\mathrm{H}_{2} \mathrm{O} \\
& \mathrm{Cl}_{2} \mathrm{O}_{3}+\mathrm{H}_{2} \mathrm{O} \rightarrow \mathrm{H}^{+}+\mathrm{HOCl}+\mathrm{ClO}_{3}^{-} \\
& \mathrm{Cl}_{2} \mathrm{O}_{3}+\mathrm{Cl}^{-}+\mathrm{H}^{+} \rightarrow \mathrm{Cl}_{2} \mathrm{O}_{2}+\mathrm{HOCl} \\
& \mathrm{Cl}_{2} \mathrm{O}_{3}+\mathrm{HClO}_{2}+\mathrm{H}_{2} \mathrm{O} \rightarrow 3 \mathrm{H}^{+}+\mathrm{Cl}^{-}+2 \mathrm{ClO}_{3}{ }^{-} \\
& \mathrm{HClO}_{2}+\mathrm{HOCl} \rightarrow \mathrm{Cl}_{2} \mathrm{O}_{2}+\mathrm{H}_{2} \mathrm{O} \\
& \mathrm{ClO}_{2}{ }^{-}+\mathrm{Cl}_{2} \mathrm{O}_{2} \rightarrow \mathrm{Cl}^{-}+2^{\circ} \mathrm{ClO}_{2} \\
& \mathrm{Cl}_{2} \mathrm{O}_{2}+\mathrm{H}_{2} \mathrm{O} \rightarrow 2 \mathrm{H}^{+}+\mathrm{Cl}^{-}+\mathrm{ClO}_{3}{ }^{-} \\
& \mathrm{ClO}_{2}^{-}+\mathrm{Cl}_{2} \mathrm{O}_{2}+\mathrm{H}_{2} \mathrm{O} \rightarrow 2 \mathrm{HOCl}+\mathrm{ClO}_{3}^{-} \\
& \mathrm{HClO}_{2}+\mathrm{Cl}^{-}+\mathrm{H}^{+} \rightarrow 2 \mathrm{HOCl} \\
& \mathrm{HClO}_{2} \rightarrow{ }^{\circ} \mathrm{ClO}+{ }^{\circ} \mathrm{OH} \\
& { }^{\cdot} \mathrm{ClO}_{2}+{ }^{\bullet} \mathrm{OH} \rightarrow \mathrm{ClO}_{3}{ }^{-}+\mathrm{H}^{+} \\
& { }^{\circ} \mathrm{ClO}_{2}+{ }^{\circ} \mathrm{ClO} \rightarrow \mathrm{Cl}_{2} \mathrm{O}_{3} \\
& \mathrm{ClO}_{2}{ }^{-}+\mathrm{H}^{+}+{ }^{\bullet} \mathrm{ClO} \rightarrow{ }^{\circ} \mathrm{ClO}_{2}+\mathrm{HOCl}
\end{aligned}
$$


The rapid de- and reprotonation processes (E1 and E2) were taken into account with equilibrium quotients given above in order to follow the small change in $\mathrm{pH}$ during the reaction. These acid dissociation reactions may be regarded as auxiliary processes, necessary only for detailed calculations; they are not central to the mechanism, represented by reactions $1-13$.

\section{Discussion}

The formation of $\mathrm{Cl}_{2} \mathrm{O}_{3}$ (reaction 1) in a rapid preequilibration was proposed by Robson as the process initiating chlorous acid decomposition. ${ }^{24}$ Later, Robson's mechanism was rejected for two reasons. ${ }^{8}$ (1) The mechanism did not explain the effect of chloride ion on the decomposition reaction. (2) Robson invoked $\mathrm{Cl}_{2} \mathrm{O}_{3}$ to explain ". . . the stabilizing effect of hydrogen peroxide on an acidic chlorate solution . . . ," but another, simpler explanation was also available. However, Robson's mechanism could have been augmented to include the effect of chloride ion, and the postulated role of $\mathrm{Cl}_{2} \mathrm{O}_{3}$ in the hydrogen peroxide/ acidic chlorate stabilization effect is not relevant to chlorous acid decomposition. Moreover, $\mathrm{Cl}_{2} \mathrm{O}_{3}$ is more than a transient; it has been synthesized and is stable below $-45^{\circ} \mathrm{C} .{ }^{10}$ Thermal explosion of chlorine dioxide vapor exhibits degenerate chainbranching, and $\mathrm{Cl}_{2} \mathrm{O}_{3}$ has been identified as the intermediate responsible for this mechanism. ${ }^{25}$ Very recently, the role of $\mathrm{Cl}_{2} \mathrm{O}_{3}$ in the hypochlorite-chlorine dioxide reaction has been discussed. $^{26}$

We reintroduce $\mathrm{Cl}_{2} \mathrm{O}_{3}$ formation for three reasons. First, it is well-known ${ }^{27}$ that the fast reversible equilibrium process

$$
2 \mathrm{HOCl} \leftrightarrow \mathrm{Cl}_{2} \mathrm{O}+\mathrm{H}_{2} \mathrm{O}
$$

takes place in aqueous solutions of $\mathrm{HOCl}$, and the third-order decomposition of hypochlorous acid into chlorate and chloride is explained ${ }^{28}$ by the further reaction of the anhydride $\mathrm{Cl}_{2} \mathrm{O}$ with $\mathrm{HOCl}$ as the rate-determining step. The formation of a "mixed" oxide, $\mathrm{Cl}_{2} \mathrm{O}_{2}$, as a first step in the reaction of $\mathrm{HOCl}$ and $\mathrm{HClO}_{2}$ is also well established. ${ }^{9}$ By analogy, one may postulate that the first step in the decomposition of $\mathrm{HClO}_{2}$ is the formation of chlorous acid anhydride, $\mathrm{Cl}_{2} \mathrm{O}_{3}$. Second, there is no need to assume the second step of Hong and Rapson's mechanism (reaction between $\mathrm{HClO}_{2}$ and $\mathrm{ClO}_{2}{ }^{-}$) in order to interpret the maximum in chlorine dioxide formation as a function of $\mathrm{pH}$. We show below that this behavior can also be explained by invoking other steps. Finally, the peculiar effect of chloride, namely, the minimum in the initial rate of decomposition as a function of chloride concentration, is partly explained by further reactions of $\mathrm{Cl}_{2} \mathrm{O}_{3}$ (see below). Direct attack of chloride either on chlorous acid or on chlorite ion alone can be ruled out as the process responsible for the unusual chloride dependence of the initial rate of decomposition, since it can only increase SR without causing a minimum in the initial rate. Hong and Rapson tried to explain this peculiar behavior via reaction between $\mathrm{HClO}_{2}$ and $\mathrm{ClO}_{2}{ }^{-}$, but, as we show later, their suggestion is contradicted by other independent experimental evidence. The structure of $\mathrm{Cl}_{2} \mathrm{O}_{3}$ is assumed to be $\mathrm{ClOCl}(\mathrm{O}) \mathrm{O}$, which was found to be the most stable structure by ab initio calculations. ${ }^{29}$

The second step (reaction 2) of our proposed mechanism consists of the $\mathrm{pH}$-independent $\left(k_{2}\right)$ and the $\mathrm{pH}$-dependent $\left(k_{2}{ }^{\prime}\right)$ hydrolysis of $\mathrm{Cl}_{2} \mathrm{O}_{3}$ to form chlorate ion and hypochlorous acid. As we have no independent determination of the equilibrium constant for reaction 1 , we have assumed a small $K_{1}$ value $(0.01$ $\left.\mathrm{M}^{-1}\right)$ with fast forward and reverse rate constants $\left(k_{1}=100\right.$ $\left.\mathrm{M}^{-1} \mathrm{~s}^{-1}, k_{-1}=10^{4} \mathrm{~s}^{-1}\right)$. The actual parameters that we are able to calculate are the products of the equilibrium constant $K_{1}$ and the rate constants $k_{2}$ and $k_{2}^{\prime}$. Although elimination of
TABLE 2: Results of Fitting

\begin{tabular}{lll}
\hline \multicolumn{1}{c}{ parameter } & \multicolumn{1}{c}{ value } & $\begin{array}{c}\text { average deviation with } \\
\text { step omitted }\end{array}$ \\
\hline$K_{1}\left(\mathrm{M}^{-1}\right)$ & 0.01 & assumed \\
$K_{1} k_{2} \times 10^{3}\left(\mathrm{M}^{-1} \mathrm{~s}^{-1}\right)$ & $1.75 \pm 0.30$ & 0.0091 \\
$K_{1} k_{2}^{\prime} \times 10^{3}\left(\mathrm{M}^{-2} \mathrm{~s}^{-1}\right)$ & $2.44 \pm 0.60$ & 0.0051 \\
$K_{1} k_{3} \times 10^{2}\left(\mathrm{M}^{-2} \mathrm{~s}^{-1}\right)$ & $5.86 \pm 1.05$ & 0.0056 \\
$K_{1} k_{4} \times 10^{2}\left(\mathrm{M}^{-2} \mathrm{~s}^{-1}\right)$ & $7.82 \pm 0.97$ & 0.0063 \\
$k_{5} \times 10^{-4}\left(\mathrm{M}^{-1} \mathrm{~s}^{-1}\right)$ & 1.55 & from literature \\
$k_{7} \times 10^{-3}\left(\mathrm{~s}^{-1}\right)$ & 1 & assumed \\
$\left(k_{6} / k_{7}\right) \times 10^{-4}\left(\mathrm{M}^{-1}\right)$ & $2.01 \pm 0.22$ & $0.0073^{a}$ \\
$\left(k_{6}^{\prime} / k_{7}\right) \times 10^{-7}\left(\mathrm{M}^{-2}\right)$ & $0.84 \pm 0.37$ & $0.0085^{b}$ \\
$\left(k_{7}^{\prime} / k_{7}\right) \times 10^{-2}\left(\mathrm{M}^{-1}\right)$ & $2.85 \pm 1.50$ & $0.0049^{c}$ \\
$\left(k_{8} / k_{7}\right) \times 10^{-4}\left(\mathrm{M}^{-1}\right)$ & $1.11 \pm 0.22$ & $0.0088^{d}$ \\
$k_{9} \times 10^{3}\left(\mathrm{M}^{-2} \mathrm{~s}^{-1}\right)$ & $3.43 \pm 0.45$ & 0.0082 \\
$k_{10} \times 10^{6}\left(\mathrm{~s}^{-1}\right)$ & $1.63 \pm 0.15$ & 0.0107 \\
$k_{11} \times 10^{-9}\left(\mathrm{M}^{-1} \mathrm{~s}^{-1}\right)$ & 2.6 & from literature \\
$k_{13} \times 10^{-9}\left(\mathrm{M}^{-1} \mathrm{~s}^{-1}\right)$ & 1 & from literature \\
$\left(k_{13} / k_{12}\right) \times 10^{1}$ & $7.18 \pm 1.27$ & $0.0085^{e}$ \\
& & $0.0043^{f}$
\end{tabular}

${ }^{a}$ Average deviation if only $k_{6}$ is omitted. ${ }^{b}$ Average deviation if only $k_{6}{ }^{\prime}$ is omitted. ${ }^{c}$ Average deviation if only $k_{7}{ }^{\prime}$ is omitted. ${ }^{d}$ Average deviation if only $k_{8}$ is omitted. ${ }^{e}$ Average deviation if only $k_{13}$ is omitted. ${ }^{f}$ Average deviation with all parameters included.

the $\mathrm{pH}$-dependent path does not increase the average deviation significantly (see Table 2), we have kept this process in the final model, because decreasing the $\mathrm{pH}$ increases the rate of decomposition of chlorous acid even in solutions containing $0.5-4.5 \mathrm{M}$ sulfuric acid. ${ }^{20,21}$ Our fitted values for $K_{1} k_{2}$ and $K_{1} k_{2}{ }^{\prime}$ yield a rate constant $\left(0.00175+0.00244\left[\mathrm{H}^{+}\right]\right) \mathrm{M}^{-1} \mathrm{~s}^{-1}$ for reaction 2 that is below that of Kieffer and Gordon, $0.0117 \mathrm{M}^{-1}$ $\mathrm{s}^{-1}$, and close to that of Hong and Rapson, $0.00275 \mathrm{M}^{-1} \mathrm{~s}^{-1}$ in the $\mathrm{pH}$ range of interest.

The third step (reaction 3) is the reaction of $\mathrm{Cl}_{2} \mathrm{O}_{3}$ with chloride to produce hypochlorous acid and $\mathrm{Cl}_{2} \mathrm{O}_{2}$. This route shifts the stoichiometry in the presence of chloride toward higher $\mathrm{SR}$ values. The parameter calculated for the third step is also the product of the equilibrium constant $K_{1}$ and the rate constant $k_{3}$. Omitting this step from the final model increases the average deviation from 0.0043 to 0.0056 ; therefore we took this step to be essential. It is interesting to note however, that reaction 3 can be replaced, without any change in the rate coefficients given in Table 2, by the following reaction:

$$
\mathrm{Cl}_{2} \mathrm{O}_{3}+\mathrm{Cl}^{-}+\mathrm{H}_{2} \mathrm{O} \rightarrow 2 \mathrm{HOCl}+\mathrm{ClO}_{2}^{-}
$$

The fourth step is a reaction of $\mathrm{Cl}_{2} \mathrm{O}_{3}$ with $\mathrm{HClO}_{2}$ to produce chlorate and chloride ions. Reaction 4 is the step that generates stoichiometric reaction $\mathrm{C}$, which produces no ${ }^{\circ} \mathrm{ClO}_{2}$, thus keeping SR low. As the $\mathrm{pH}$ increases, the distribution of chlorine(III) species shifts from chlorous acid to chlorite ion, and reaction pathways leading to stoichiometric reactions $\mathrm{A}$ and $\mathrm{B}$, both of which produce ${ }^{\cdot} \mathrm{ClO}_{2}$, begin to compete more effectively with the pathway leading to stoichiometry $\mathrm{C}$. Consequently, the increase in ${ }^{\circ} \mathrm{ClO}_{2}$ relative to $\mathrm{ClO}_{3}{ }^{-}$increases $\mathrm{SR}$. Moreover, this reaction is responsible for the maximum in the initial rate of chlorine dioxide formation in the absence of chloride ion without any corresponding maximum in the initial rate of consumption of $\mathrm{Cl}$ (III) as a function of $\mathrm{pH}$. The inclusion of this step requires that the stoichiometric equations be augmented by equation $\mathrm{C}$. The actual parameter calculated for the fourth step is also the product of equilibrium constant $K_{1}$ and $k_{4}$. Omitting this reaction would not only increase the average deviation significantly, as seen in Table 2, but we would also lose an important property of the mechanism, the maximum in the initial rate of chlorine dioxide formation as a function of 
$\mathrm{pH}$. We therefore find reaction 4 to be an essential component of the mechanism. We also note that reaction 4 cannot be replaced by reaction 15 :

$$
\mathrm{HClO}_{2}+\mathrm{Cl}_{2} \mathrm{O}_{3} \rightarrow \mathrm{Cl}_{2} \mathrm{O}_{2}+\mathrm{ClO}_{3}^{-}+\mathrm{H}^{+}
$$

because the average deviation would increase significantly from 0.0043 to 0.0083 .

The fifth crucial step is reaction 5, the well-known ratedetermining step of the hypochlorous acid-chlorous acid reaction. ${ }^{11}$ This reaction has been thoroughly studied and found to be subject to general acid catalysis. ${ }^{30} \mathrm{We}$ used the experimentally determined rate constant, ${ }^{11} 1.55 \times 10^{4} \mathrm{M}^{-1} \mathrm{~s}^{-1}$, to start our fitting procedure.

Reactions 6-8 are fast processes, only the ratios of their rate coefficients could be calculated from our experiments. Reactions 6 and 7 are well-known reactions of $\mathrm{Cl}_{2} \mathrm{O}_{2}$. The only new feature is that both reactions have chloride-catalyzed pathways, which has not been proposed before. The catalyzed pathways probably go through the equilibrium E4, but since we do not have independent experimental evidence for this step, we have not included it in the final model.

$$
\mathrm{Cl}_{2} \mathrm{O}_{2}+\mathrm{Cl}^{-} \leftrightarrow \mathrm{Cl}_{3} \mathrm{O}_{2}^{-}
$$

If the chloride-catalyzed path of reaction 6 is eliminated from the model, the average deviation increases significantly, as seen from Table 2. We therefore include this path in our mechanism. Neglecting the chloride-catalyzed path of the hydrolysis of $\mathrm{Cl}_{2} \mathrm{O}_{2}$ causes only a minor increase in the average deviation, but significant deviation between the measured and calculated data occur at low initial chlorite concentrations. Including both reactions 6 and 8 may appear strange, but these processes can readily be understood in terms of the recently proposed ${ }^{31}$ shortlived intermediate $\mathrm{ClOCl}(\mathrm{O}) \mathrm{OClO}^{-}$. Loss of the terminal chloride leads to the unstable dimer of chlorine dioxide, which decomposes rapidly to give $2{ }^{\circ} \mathrm{ClO}_{2}$ (reaction 6), while loss of $\mathrm{ClO}^{-}$leads to the products of reaction 8 . This step cannot be replaced by

$$
\mathrm{Cl}_{2} \mathrm{O}_{2}+\mathrm{ClO}_{2}^{-}+\mathrm{H}^{+} \rightarrow \mathrm{HOCl}+\mathrm{Cl}_{2} \mathrm{O}_{3}
$$

since the average deviation would increase drastically from 0.0043 to 0.0093 . Therefore, instead of monomolecular $\mathrm{ClO}^{-}$ cleavage from the $\mathrm{ClOCl}(\mathrm{O}) \mathrm{OClO}^{-}$adduct to produce two hypochlorous acid molecules and a chlorate ion, we suggest a different pathway. A bimolecular attack of the oxygen of $\mathrm{ClO}_{2}{ }^{-}$ on the inner chlorine of $\mathrm{Cl}_{2} \mathrm{O}_{2}$ followed by reaction of $\mathrm{H}_{2} \mathrm{O}$ with this adduct also leads to two hypochlorous acid molecules and a chlorate ion.

The effects of chloride ion on the chlorous acid decomposition kinetics are complex and contradictory. ${ }^{26}$ Hong and Rapson noted that their mechanism contained an autocatalytic sequence of steps even though the S-shaped kinetics curve characteristic of autocatalysis was not observed. Their sequence is reaction 9 followed by two additional reactions: reverse of chlorine hydrolysis to produce chlorine $\left(k_{\mathrm{r}}\right)$ and consumption of chlorine by chlorous acid $\left(k_{\mathrm{c}}\right)$. We believe this sequence is unlikely for the following reasons. During the slow decomposition reaction the hydrolysis of chlorine would be a rapidly equilibrated, not an irreversible, reaction. ${ }^{32}$

Hong and Rapson calculated the rate constant ratio $k_{5} / k_{\mathrm{r}}=$ 0.00165 , from which the rate coefficient of the rate-determining step of the hypochlorous acid-chlorous acid reaction should be $29.7 \mathrm{M}^{-1} \mathrm{~s}^{-1}$, since $k_{\mathrm{r}}=1.8 \times 10^{4} \mathrm{M}^{-2} \mathrm{~s}^{-1} .{ }^{33}$ This value is roughly 3 orders of magnitude smaller than that obtained from independent experimental studies! ${ }^{11,34}$ The reaction of aqueous chlorine with chlorous acid would be considerably faster than the reaction of hypochlorous acid with chlorous acid. ${ }^{35}$

We therefore conclude that the reverse of chlorine hydrolysis cannot be responsible for the inhibitory effect of chloride ion. The net effect of reactions $6,6^{\prime}, 7,7^{\prime}$, and 9 accounts for the unusual chloride ion dependence of the initial rate of decomposition. Our value of $k_{9}=0.00343 \mathrm{M}^{-2} \mathrm{~s}^{-1}$ lies within the previously reported range, which includes determinations of $0.000483,{ }^{6} 0.0018,{ }^{7}$ and $0.014^{5} \mathrm{M}^{-2} \mathrm{~s}^{-1}$.

Reactions E1, E2, and 1-9, which contain the two intermediates $\mathrm{Cl}_{2} \mathrm{O}_{2}$ and $\mathrm{Cl}_{2} \mathrm{O}_{3}$, constitute a minimal framework for a qualitative description of the decomposition of chlorous acid. This set of reactions fits the data quantitatively over the first $24 \mathrm{~h}$ of reaction. With an average deviation of 0.0107 for the full data set, however, this mechanism as it stands does not satisfy the stringent quantitative criterion that we set forth initially, i.e., that the average deviation between measured and calculated absorbances approach the experimental error of 0.004 . To reach this goal, we invoke reaction 10 . This step is not without its difficulties, but it is essential to obtain the high quality of fit that we demand. Reactions $11-13$ are then included to account for the fates of the species produced by reaction 10 .

Reaction 10 has not been proposed before. All our attempts to fit the long-time data quantitatively without a first-order decomposition step failed. As we shall see later, although the half-time of this reaction is more than 4 days, it still plays a key role in describing our experimental results. Omitting the first-order decomposition from the model drastically increases the average deviation from 0.0043 to 0.0107 (see Table 2). Therefore the first-order decomposition of chlorous acid is included in the model. For HOClO, only three bond-breaking decomposition modes are possible. If we consider breaking one bond at a time so that the products are ions (heterolytic bond cleavage), then this process leads to three first-order decomposition channels. The one yielding $\mathrm{H}^{+}+\mathrm{ClO}_{2}{ }^{-}$is dissociation. The remaining two channels, leading to $\mathrm{OH}^{-}+\mathrm{ClO}^{+}$and $\mathrm{HOCl}^{+}+\mathrm{O}^{-}$are so thermodynamically unfavorable, $\Delta_{\mathrm{R}} G^{\circ}$ -values 502 and $1235 \mathrm{~kJ} / \mathrm{mol}$, respectively, that we consider them implausible. Therefore, heterolytic first-order decomposition is unlikely.

Breaking one bond at a time so that the products are uncharged (homolytic bond cleavage) also yields three decomposition modes with positive standard free energies of reaction: $\cdot{ }^{\bullet} \mathrm{OH}+{ }^{\bullet} \mathrm{ClO}(128 \mathrm{~kJ} / \mathrm{mol}),{ }^{36,37} \mathrm{HOCl}+{ }^{\bullet} \mathrm{O} \bullet(165 \mathrm{~kJ} / \mathrm{mol})$, $\cdot \mathrm{H}+{ }^{\bullet} \mathrm{ClO}_{2}(336 \mathrm{~kJ} / \mathrm{mol})$. We select the least thermodynamically unfavorable channel, $\mathrm{HOClO} \rightarrow{ }^{\bullet} \mathrm{OH}+{ }^{\bullet} \mathrm{ClO}$. If we assume that the rate of the reverse radical-radical reaction is close to the diffusion-controlled limit $\left(k_{-10}=5 \times 10^{9} \mathrm{M}^{-1} \mathrm{~s}^{-1}\right)$, calculating the free energy change for reaction 10 from the quotient of the forward and reverse rates yields a value of 88 $\mathrm{kJ} / \mathrm{mol}$, significantly lower than obtained from the available thermodynamic data. Two explanations suggest themselves to account for this discrepancy. One is that relatively small $(\sim 20$ $\mathrm{kJ} \mathrm{mol}^{-1}$ each) errors in the standard free energies of the radical products $^{36}$ could result in an overestimate of the magnitude of $\Delta_{\mathrm{R}} G^{\circ}$ for the reaction. A more likely explanation is that, despite our best efforts to exclude light, the analyzing light from the spectrophotometer is sufficient to drive reaction 10 photochemically. In this case, our minimal framework of reactions E1, E2, $1-9$, constitutes the mechanism of the thermal reaction, and reactions $10-13$ are necessary to describe the photochemical contribution to the observed data. While one might expect such 


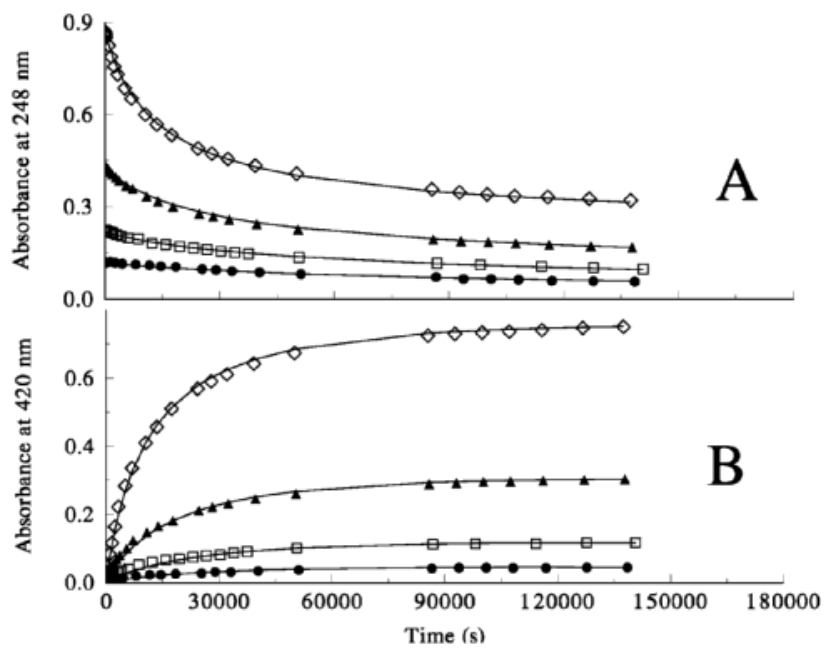

Figure 8. Experimentally measured (symbols) and calculated (solid lines) absorbances at $248 \mathrm{~nm}(\mathrm{~A})$ and $420 \mathrm{~nm}(\mathrm{~B})$ at $\mathrm{pH}=1.3$ and $\left[\mathrm{Cl}^{-}\right]_{0}=0 \mathrm{M}$ at different $[\mathrm{Cl}(\mathrm{III})]_{0}=\left[\mathrm{HClO}_{2}\right]_{0}+\left[\mathrm{ClO}_{2}{ }^{-}\right]_{0}$ concentrations. $[\mathrm{Cl}(\mathrm{III})]_{0}=0.001(\bullet), 0.002(\square), 0.004(\mathbf{\Delta}), 0.008(\diamond)(\mathrm{M})$.

a photochemically driven reaction to give relatively large deviations from experiment to experiment, which we have not seen, a similar phenomenon, involving the photochemically induced oscillatory decomposition of tetrathionate ${ }^{38}$ in the presence of analyzing light, gives quite reproducible behavior. At any rate, since no satisfactory fit could be obtained without a first-order decomposition channel, we conclude that including reaction 10 provides the most satisfactory description of the system under the conditions of our experiments. Of course, it is also possible that our experiments are subject to some artifact of indeterminate nature, whose effects manifest themselves only over very long times ( $>24 \mathrm{~h}$ ).

Rate constants for reactions of several scavengers with $\bullet \mathrm{OH}$ radical are available. ${ }^{39,40} \mathrm{We}$ tested the impacts of several such reactions on the quality of the fit and found that reaction 11 is the only significant fate of the ${ }^{\circ} \mathrm{OH}$ radical formed in reaction 10. The main ${ }^{\circ} \mathrm{ClO}$ scavenging reactions are 12 and 13 . The rate constant for reaction 13 has been measured. ${ }^{41}$ From the best-fit calculated ratio $k_{13} / k_{12}=0.718$ and the measured $k_{13}=$ $1 \times 10^{9} \mathrm{M}^{-1} \mathrm{~s}^{-1}$ we calculate $k_{12}=1.4 \times 10^{9} \mathrm{M}^{-1} \mathrm{~s}^{-1}$, which is reasonable for a diffusion-controlled radical-radical reaction.

Although only reaction 1 appears in our final model as a reversible step, in the early stages of the fitting procedure all possible mono- and bimolecular reactions, among them the back reactions of eqs $2,3,5-7,9,10,12$, were included. Our simulations revealed that none of them was necessary to describe the measured kinetic curves.

Figures 8A,B; 9A,B; and 10A,B show measured and calculated kinetic curves of decomposition of chlorous acid. The agreement between these data, the lack of systematic deviation, and the low value of the average deviation lend support to our proposed mechanism. Our "acceptable limit of error" is a value close to the error of the absorbance measurement for the spectrophotometer used, about \pm 0.004 absorbance unit. Since the average deviation was found to be 0.0043 , we believe that our fitting result is close to the experimentally achievable limit of error. The calculated values of the parameters are summarized in Table 2. The rate constants used in the final simulations are easily obtained from the fitted ratios and the literature or assumed values contained in Table 2 .

\section{Conclusion}

Accounting for all major characteristics of the experimental curves requires every step in the proposed mechanism. If any

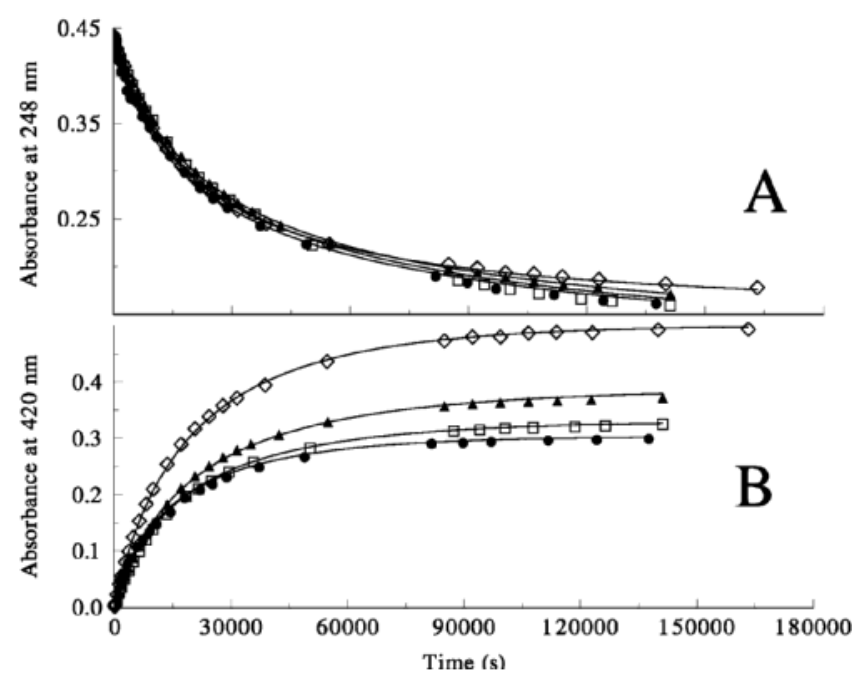

Figure 9. Experimentally measured (symbols) and calculated (solid lines) absorbances at $248 \mathrm{~nm}$ (A) and $420 \mathrm{~nm}$ (B) at $\mathrm{pH} 1.1$ and $\left[\mathrm{HClO}_{2}\right]_{0}+\left[\mathrm{ClO}_{2}^{-}\right]_{0}=0.004 \mathrm{M}$ at different initial chloride concentrations. $\left[\mathrm{Cl}^{-}\right]_{0}=0(\bullet), 0.001(\square), 0.003(\mathbf{\Delta}), 0.01(\diamond)(\mathrm{M})$.

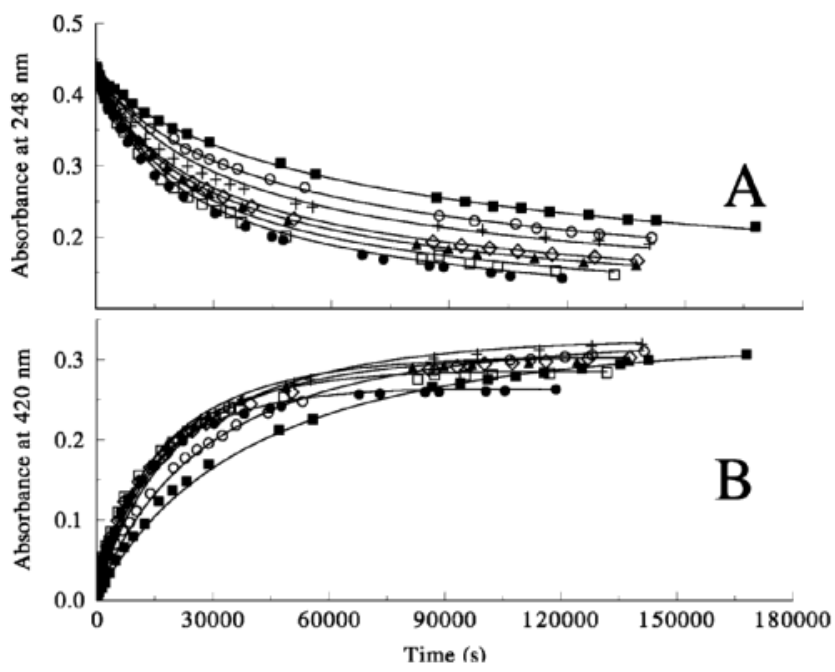

Figure 10. Experimentally measured (symbols) and calculated (solid lines) absorbances at $248 \mathrm{~nm}(\mathrm{~A})$ and $420 \mathrm{~nm}(\mathrm{~B})$ at $\left[\mathrm{HClO}_{2}\right]_{0}+$ $\left[\mathrm{ClO}_{2}{ }^{-}\right]_{0}=0.004 \mathrm{M}$ at different $\mathrm{pH}$ values and $\left[\mathrm{Cl}^{-}\right]_{0}=0 \mathrm{M}: \mathrm{pH}=$ $0.7(\bullet), 0.9(\square), 1.1(\mathbf{\Delta}), 1.3(\diamond), 1.5(+), 1.7(\bigcirc), 1.9(\square)$.

steps were to be omitted, then either the average deviation would exceed the acceptable limit of error, or an important property of the model would be lost. For example, Kieffer and Gordon followed the reaction for $1-8 \mathrm{~h}$ and derived their rate equation from $\mathrm{Cl}(\mathrm{III})$ consumption. If we use our absorbance values at $248 \mathrm{~nm}$, which arise mainly from $\mathrm{Cl}(\mathrm{III})$, and fit their mechanism to our data, the fit is excellent: average deviation 0.0068 . However, when their mechanism is applied to the entire data set, evaluating $\mathrm{Cl}$ (III) consumption and chlorine dioxide formation simultaneously, then a much higher, unacceptable average deviation of 0.0165 is obtained. Hong and Rapson derived their rate expression from the initial rate of chlorine dioxide formation. If we select the data points for $t<3600 \mathrm{~s}$ and use only absorbances at $420 \mathrm{~nm}$, the fitting is acceptable: average deviation 0.0069 . The implication of these calculations is that the previous models are not in disagreement with the portions of our data taken under the conditions that most closely correspond to the data collected earlier.

One example of an important property of the mechanism that would be lost if any steps were to be omitted is the steady increase in the rate of decomposition with decreasing $\mathrm{pH}$. If 
the $\mathrm{pH}$-dependent hydrolysis of $\mathrm{Cl}_{2} \mathrm{O}_{3}$ is neglected, the decomposition rate for the resulting mechanism shows saturation behavior as the $\mathrm{pH}$ is decreased.

On the methodological side, the most important conclusion that may be drawn from this study is that complex kinetic systems are best studied by using recently developed experimental and computational techniques and the entire available concentration-time series, rather than by initial rate studies alone. Only large amounts of data over a broad range of conditions can provide sufficiently stringent tests of proposed mechanisms for such reactions, where different sets of species may determine the behavior at different stages of the reaction. Methods for multiwavelength analysis offer a particularly powerful tool when several absorbing species are present. By combining the availability of large data sets at multiple wavelengths over the entire course of the reaction with the computational power to analyze these data and fit them to the results of extensive simulations, it should be possible to generate reliable kinetic models and plausible mechanisms for even the most complex of systems.

The decomposition of chlorous acid is a venerable reaction with a long and distinguished history of study. ${ }^{8}$ This challenging reaction presented a puzzle, because of its complex kinetics and stoichiometry. The resolution of this puzzle presented here brings out an important characteristic of halogen oxidationreduction reactions: mechanistically, they do not fit into a single neat category. The decomposition of chlorous acid exhibits both of the major mechanisms of halogen redox chemistry. Some steps in the mechanism, such as reaction 5, oxidation of chlorous acid by hypochlorous acid, are examples of inner-sphere atom transfer reactions. In this case, we have oxygen atom transfer, ${ }^{31}$ although oxychlorine species are capable of $\mathrm{Cl}^{+}$transfer as well. ${ }^{42}$ Other steps, such as reaction 13 , oxidation of chlorite ion by chlorine monoxide, are examples of outer-sphere electron transfer. ${ }^{41}$ A further reminder of the multi-faceted and surprising chemistry exhibited by such deceptively simple oxyhalogen molecules and ions is the need to invoke in the mechanism radical formation by homolytic scission of chlorous acid to explain the long-time behavior. We have noted the uncertainties still associated with this particular step. This complex picture is further amplified by the transitory intermediates that provide branching points in the kinetics pathways of chlorous acid decomposition. The unsymmetrical $\mathrm{Cl}_{2} \mathrm{O}_{2}$ intermediate, essential for explaining radioactive chlorine tracer studies of oxidation state changes among mixtures of chlorine species, ${ }^{9}$ is present in the mechanism. So, too, is the $\mathrm{Cl}_{2} \mathrm{O}_{3}$ intermediate, essential for explaining explosion, i.e., chain-branching, in gas-phase chlorine dioxide. ${ }^{25}$ With their ability to participate in different mechanistic pathways, and to generate radicals and other highly reactive intermediate species, it is no wonder that oxyhalogen species in general, and chlorite ion in particular, are such useful reagents for bleaching, disinfection, and destruction of harmful waste products by oxidation of substrates to useful or nontoxic end-products.

Acknowledgment. This work was supported by the National Science Foundation (Grant CHE-9988463), the Hungarian Science Foundation (OTKA Grant Nos. T30446 and T029838), and the U.S.-Hungarian cooperative program. A. K. H. is grateful for the financial support of OTKA postdoctoral fellowship Grant No. D38001. We thank an anonymous reviewer for pointing out the complexities of reaction 10 .

Supporting Information Available: Figures of all experimental and calculated curves as well as data files containing the experimental and fitted data are available. This material is available free of charge via the Internet at http://pubs.acs.org.

\section{References and Notes}

(1) Epstein, I. R.; Orbán, M. In Oscillations and Traveling Waves in Chemical Systems; Field, R. J., Burger, M., Eds.; Wiley: New York, 1985; pp $258-286$.

(2) (a) Citri, O.; Epstein, I. R. J. Phys. Chem. 1987, 91, 6034-6040.

(b) Citri, O.; Epstein, I. R. J. Phys. Chem. 1988, 92, 1865-1871.

(3) Frerichs, G. A.; Minarik, T. M.; Grun, R. J.; Thompson, R. C. J. Phys. Chem. A 2001, 105, 829-837.

(4) Rábai, Gy.; Orbán, M. J. Phys. Chem. 1993, 97, 5935-5939.

(5) (a) Kieffer, R. G.; Gordon, G. Inorg. Chem. 1968, 7, 235-239.

(b) Kieffer, R. G.; Gordon, G. Inorg. Chem. 1968, 7, 239-244.

(6) Hong, C. C.; Rapson, W. H. Can. J. Chem. 1968, 46, 2053-2060.

(7) Schmitz, G.; Rooze, H. Can. J. Chem. 1985, 63, 975-980.

(8) Gordon, G.; Kieffer, R. G.; Rosenblatt, D. H. In Progress in Inorganic Chemistry; Lippard, S. J., Ed.; John Wiley and Sons: New York, 1972; Vol. 15, pp 201-286.

(9) Taube, H.; Dodgen, H. J. Am. Chem. Soc. 1949, 71, 3330-3336. 2797.

(10) McHale, E. T.; von Elbe, G. J. Am. Chem. Soc. 1967, 89, 2795-

(11) Peintler, G.; Nagypál, I.; Epstein, I. R. J. Phys. Chem. 1990, 94, $2954-2958$

(12) IUPAC Stability Constant Database; Royal Society of Chemistry,

1992-1997.

(13) Stanbury, D. M.; Figlar, J. N. Coord. Chem. Rev. 1999, 187, 223-232.

(14) Zékány, L.; Nagypál, I.; Peintler, G. PSEQUAD for Chemical Equilibria; Technical Software Distributors: Szeged, Hungary, 1991.

(15) (a) Peintler, G.; Nagypál, I.; Jancsó, A.; Epstein, I. R.; Kustin, K. J. Phys. Chem. A 1997, 101, 8013-8020. (b) Peintler, G.; Nagypál, I.; Epstein, I. R.; Kustin, K. J. Phys. Chem. A 2002, 106, 3899-3904.

(16) Peintler, G. ZiTa, Version 5.0, A Comprehensive Program Package for Fitting Parameters of Chemical Reaction Mechanism; Attila József University:, Szeged, Hungary, 1989-1998.

(17) Masschelein, W. J. Chlorine Dioxide; Ann Arbor Science: Ann Arbor, 1979.

(18) Buser, W.; Hänisch, H. Helv. Chim. Acta 1952, 35, 2547-2556.

(19) White, J. F.; Taylor, M. C.; Vincent, G. P. Ind. Eng. Chem. 1942, 34, $782-792$.

(20) Ni, Y.; Yin, G. Ind. Eng. Chem. Res. 1998, 37, 2367-2372.

(21) Yin, G.; Ni, Y. Can. J. Chem. Eng. 1998, 76, 921-926.

(22) Jenkin, M. E.; Saunders: S. M.; Pilling, M. J. Atmos. Environ 1997, 31, 81-104.

(23) Broadbelt, L. J.; Stark, S. M.; Klein, M. T. Chem. Eng. Sci. 1994, 49, 4991-5010

(24) Robson, H. L. In Kirk-Othmer: Encyclopedia of Chemical Technology, 2nd ed.; Interscience: New York, 1964; Vol. 5, pp 27-50.

(25) McHale, E. T.; von Elbe, G. J. Phys. Chem. 1968, 72, 1849-1856.

(26) Csordás, V.; Bubnis, B.; Fábián, I.; Gordon, G. Inorg. Chem. 2001, 40, 1833-1836

(27) Beach, M. W.; Margerum, D. W. Inorg. Chem. 1990, 29, 12251232.

(28) Adam, L. C.; Fábián, I.; Suzuki, K.; Gordon, G. Inorg. Chem. 1992, $31,3534-3541$

(29) Clark, J.; Francisco, J. S. J. Phys. Chem. A 1997, 101, 7145-7153. (30) Furman, C. S.; Margerum, D. W. Inorg. Chem. 1998, 37, 43214327.

(31) Jia, Z. J.; Margerum, D. W.; Francisco, J. S. Inorg. Chem. 2000, $39,2614-2620$

(32) Wang, T. X.; Margerum, D. W. Inorg. Chem. 1994, 33, 10501055

(33) Eigen, M.; Kustin, K. J. Am. Chem. Soc. 1962, 84, 1355-1361.

(34) Gordon, G.; Tachiyashiki, S. Environ. Sci. Technol. 1991, 25, 468474.

(35) Emmenegger, F.; Gordon, G. Inorg. Chem. 1967, 6, 633-635.

(36) Stanbury, D. In Advances in Inorganic Chemistry; Sykes, A. G., Ed; Academic Press: San Diego, 1989; Vol. 33, pp 69-138.

(37) Mussini, T.; Longhi, P. In Standard Potentials in Aqueous Solution; Bard, A. J., Parsons, R., Jordan, J., Eds.; Marcel Dekker: New York, 1985 pp 70-77.

(38) Horváth, A. K.; Nagypál, I.; Epstein, I. R. J. Am. Chem. Soc. 2002, 124, 10956-10957.

(39) Klaning, U. K.; Sehested, K. J. Phys. Chem. 1991, 95, 740-743.

(40) Ross, A. B.; Mallard, W. G.; Helman, W. P.; Buxton, G. V.; Huie, R. E.; Neta, P. NDRL-NIST Solution Kinetics Database:-Version 3.0; Notre Dame Radiation Laboratory: Notre Dame, IN, and National Institute of Standards and Technology: Gaithersburg, MD, 1998.

(41) Eriksen, T. E.; Lind, J.; Merényi, G. J. Chem. Soc., Faraday Trans. 1981, 77, 2115-2123. 4851. 